an integral part of care delivery. ${ }^{2}$ The study mentioned in Dr Jenkins' letter strengthens the evidence base for the contribution of ward privacy to violence reduction. ${ }^{3}$ As that letter also indicates, measures have largely remained focused on clinical outcomes and any research can only hint at the key design components that drive these changes. Our review emphasised the need for patient-focused outcomes and their involvement in ward design. We have developed some novel methodology that can highlight positive and negative issues in current design from the patient perspective and have also developed measures to monitor the effects of changes in ward design. We hope that tools enabling robust, patient-centred evaluation of in-patient facilities might contribute to the recognition of the complex contribution of the material environment - in its physical and psychosocial dimensions - to patient outcomes.

1 Papoulias C, Csipke E, Rose D, Mckellar S, Wykes T. Design in mind: the psychiatric ward as therapeutic space: a systematic review. Br J Psychiatry 2014; 205: 171-6.

2 Department of Health. Health Building Note 03-01: Adult Acute Mental Health Units. The Stationery Office, 2013.

3 Jenkins $\mathrm{O}$, Dye S, Foy C. A study of agitation, conflict and containment in association with change in ward physical environment. J Psychiatr Intensive Care 2014; 1: 1-9.

Emese Csipke, Institute of Psychiatry, King's College London. Email:

emese.1.csipke@kcl.ac.uk

doi: $10.1192 / \mathrm{bjp} .206 .3 .252 \mathrm{~b}$

\section{Discharges to prison \\ from medium secure psychiatric units}

The percentage of patients being discharged to prison from medium secure units has nearly doubled to $20 \%$ in just over a decade. The research captures a significant change in the practice of forensic psychiatry in England and Wales. When this area was discussed within the London region several years ago, colleagues who said that they were not doing this looked into the matter and found that they were. Doyle et $a l^{1}$ do not report any variation in practice, which suggests there has been a uniform change (across the relevant services).

In considering why this has happened, the authors present a rather negative picture of sending back still-symptomatic, higher-risk people to prison, with inadequate aftercare. An alternative view is that this represents a new realism in forensic psychiatry. Medium secure provision has greatly expanded in the last 25 years but, as shown by the paper, the system is risk averse to community discharges. Such patients have low symptoms and stay longer in hospital. It is unlikely that more money will be allocated to forensic services and we have to make the best use of the resources we have.

In East London, appropriately transferring patients back to prison, alongside an improved rate of community discharge and the consistency of an admissions panel, has helped to manage demand. The service has gone from a waiting list of 25 patients to having beds quickly available for people presenting as acutely psychotic in prison. This is despite only sending people to the independent sector in exceptional cases and having no expansion in relevant beds over the time period.

The research is consistent with a change in the model that forensic psychiatrists have about prisoners. In the past, sending people with a diagnosis of psychotic mental illness back to prison was generally seen as inappropriate. Forensic psychiatry saw itself as having redeeming and containing roles, through identifying the mentally ill in prison, transferring them to medium security, providing treatment, and then either discharging to the community or providing longer-term secure care if the person's risk and/or illness could not be satisfactory managed.

The model now seems to regard prison as a form of 'community', to which some prisoners will be returned after being treated in hospital. It is logical that the relevant groups should be those for whom safe and effective ordinary discharge is unlikely. They may have a primary diagnosis of mental illness, but this might not be the primary problem for a significant group (e.g. career criminals and those who committed serious offences unrelated to mental illness). It is acknowledged that some practitioners will not welcome this philosophical and practice shift.

The fate of those returning to prison is an issue for both commissioning and service provision. NHS forensic and/or general adult services should follow up all those who are returned to prison. They should remain in the care programme approach (CPA) process, with 6-monthly CPA reviews and a local care coordinator who keeps in regular contact with them. This would assist with monitoring, management of relapses and aftercare. In East London, we have a consultant and community nurse with prison roles that include helping to manage returned prisoners. Although mental health prison in-reach is variable, such arrangements help provide a framework for prison aftercare.

In respect of the idea of a prison hospital, as advanced in the paper, this is the approach in South Australia (and elsewhere). Other than for patients found unfit or insane, most patients have the master status of prisoner, whether on remand or sentenced. At the end of their prison sentence, or if their remand ends, they have to be released from the forensic hospital, but can ordinarily be detained in a non-forensic mental health unit. This system has the disadvantage that there are no hospital orders.

A combination approach has merit. Hospital orders could be used for those who require a hospital care pathway and the court could still order people to hospital otherwise (e.g. for a trial of treatment). Mentally ill prisoners would receive more prompt treatment in a hospital within the prison estate. Each major metropolitan area or part of England and Wales could have such a prison hospital (regulated as usual by the Care Quality Commission). Prisoners could be informal patients, whereas currently they are being denied the 'least restrictive' approach enshrined within the Mental Health Act 1983. This would bring prison psychiatry in line with ordinary adult psychiatry practice. The underused hybrid order could be resuscitated for intermediate cases.

It is therefore to be hoped that this paper will promote active consideration of the best way to manage patients presenting in prison. I note that, unfortunately, the seminal study by Coid et al of half the secure units in England and Wales, ${ }^{2}$ which showed marked variation in the practice of forensic psychiatry, was not presented and discussed at an annual forensic conference. As a specialty we should not miss the opportunity to discuss this highly relevant piece of research.

1 Doyle M, Coid J, Archer-Power L, Dewa L, Hunter-Didrichsen A, Stevenson R, et al. Discharges to prison from medium secure psychiatric units in England and Wales. Br J Psychiatry 2014; 205: 177-82.

2 Coid J, Kahtan N, Gault S, Cook A, Jarman B. Medium secure forensic psychiatry services: comparison of seven English health regions. $\mathrm{Br} J$ Psychiatry 2001; 178: 55-61.

Neil Boast, Consultant Forensic Psychiatrist, London. Email: Neil.Boast@eastlondon.nhs.uk

doi: $10.1192 /$ bjp.206.3.253 